\section{THE GREAT MADRID METEOR.}

$\mathrm{N}$ Monday, February Io, at $9 \mathrm{~h} .29 \mathrm{~m}$. 30s., there was observed an instantaneous bluish-white illumination in the atmosphere, so strong and vivid as to be visible in the inner rooms and in the open air.

The day was a magnificent one : blue sky, no wind, and a radiant sun.

Soon after there was plainly visible near the zenith, and some few degrees to the south-east, a white spot, like smoke, bearing north-east to south-west, of about $6^{\circ}$ length and $I^{\circ}$ wide ; its form was semicircular, with the convexity turned to the east. In the centre, and near the apex of the curve, it presented a condensation of a reddish colour, similar to those of clouds at sunset. The general appearance of the spot. was that of a light cirro-cumulus.

At 9 h. 3om. 40s. there was heard a deep and very strong detonation, accompanied by many others not so intense, similar to the noise produced by a large cannon-ball running along the upper storey of a house. This noise was very prolonged; it was found to last two minutes.

Meanwhile the vibration of windows and partitions (not the thick walls) was extraordinary, and the rattling of panes of glass alarming. In some houses all the window-glasses were broken.

Judging from the time which elapsed between the light and the sound of the first detonation, the meteor exploded in the air at a distance not inferior to 24 kilometres; and this number is evidently too low.

Considering the aspect of the spot of smoke, it seems probable that the meteor proceeded from the south-east towards the north-west, and that near the zenith of Madrid it exploded.

Changed into smoke and dust, totally or partially, this smoke was carried away by the superior currents of the atmosphere to the east. We find here a splendid confirmation of the theory which supposes that, at the upper limits of the air, the wind moves from west to east.

In the accompanying rough sketch, one part corresponds to the trajectory of the celestial body; and the other, which forms an angle with the first, to the action of the aerial current.

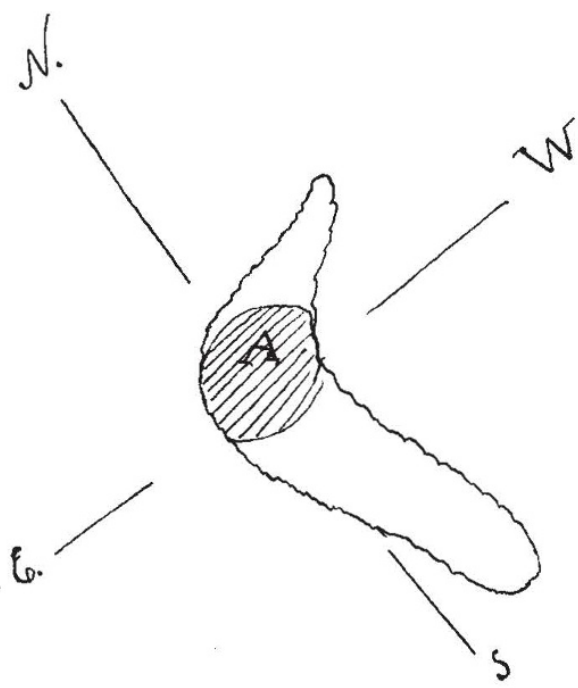

FIG. r.-Aspect and position of the cloud some minutes after the explosion. A, Condensation of a reddish colour.

The accompanying photograph of the phenomenon was taken by an amateur some few minutes after the explosion.

The cloud continued its course to the E.N.E., or E. $\frac{1}{4}$ N.E., dissolving gradually away, and at 3 h. p.m. it was still perfectly visible like a light cirrus in the east at some $20^{\circ}$ above the horizon.

The compression of the atmosphere in the instant of the conflagration was indicated by the registering barometers. In the aneroids the trace is small; but in the mercurial one the column rose $\mathrm{r} \cdot 6 \mathrm{~m} . \mathrm{m}$., and lowered 0.7 m.m., the amplitude of the total oscillation being $2 \div 3$ m.m.

In the neighbourhood of Madrid some fragments of the meteor fell, and I have obtained one of them.

W

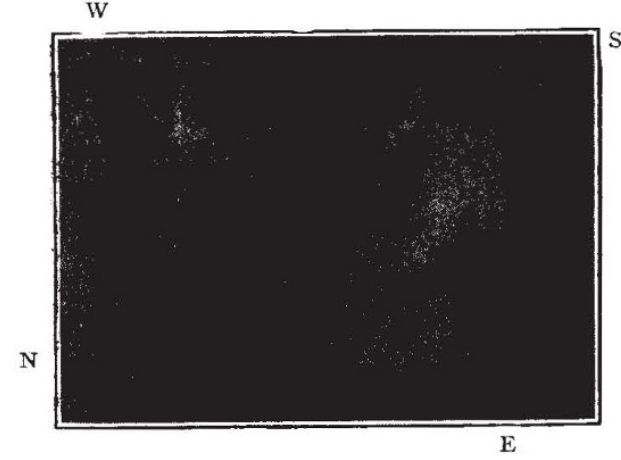

FIG. 2,- Photograph of the cloud immediately after the explosion.

Externally the fragment is of a black metallic aspect ; inside it is of white stony appearance, with some brilliant points like nickel ; it weighs 6.3 grams.

From information received later, it appears that the phenomenon was visible in a large part of the Peninsula, from Sierra de Estrella (Portugal) to Denia in the Mediterranean coast, and from Segovia to Aguilas, or a distance of 700 kilometres from east to west, and 400 from north to south. These are inferior limits.

AUGUSTO ARCIMIS.

\section{THE FRILLED LIZARD: "CHLAMYDOSAURUS KINGI."}

THE above-named lizard inhabits the northern or tropical territories of the Australian continent, and is tolerably abundant in both North Queensland and the Kimberley district of Western Australia. Its earliest record is that given by Captain Philip P. King, in his " Narrative of a Survey of the Intertropical Coasts of Australia" (1826), and wherein it is named, figured, and described in a Natural History Appendix by Dr. J. E. Grey.

The habitat of the frilled lizard is essentially sylvan, its resort being the thickly-wooded scrublands, and its favourite abiding-place the trunks and lower limbs of the larger trees. The length of the finest examples rarely exceeds three feet, and of this the long, rough, though slender tail monopolises the greater moiety. Living specimens exhibit a considerable individual colour variation. The predominant hue of the body is pale brown with reticulated markings; while the frill, in the males more especially, is usually decorated with interblending tints of yellow, scarlet, and steel-blue.

No living example of this singular lizard had, up to the present year, been brought alive to Europe, a circumstance which will account, to a large measure, for the fact of certain abnormal phenomena connected with its lifehabits having hitherto attracted little or no scientific attention. Through the possession of living specimens of Chlamydosaurus in both Queensland and Western Australia, several interesting data concerning the species have fallen within my notice. Having, furthermore, succeeded in bringing one out of several examples embarked safely to England, my presentation of the animal to the

NO. I 374, VOL. 53] 